\title{
Protective effect of the DNA vaccine encoding the major house dust mite allergens on allergic inflammation in the murine model of house dust mite allergy
}

\author{
Nacksung Kim¹, Soon Seog Kwon², Jaechun Lee ${ }^{3,4}$, Sohyung Kim ${ }^{4}$ and \\ Tai June Yoo*4
}

Address: ${ }^{1}$ Medical Research Center for Gene Regulation, Chonnam National University Medical School, Gwangju, Korea, ${ }^{2}$ Department of Internal Medicine, Catholic University Medical School, Seoul, Korea, ${ }^{3}$ Department of Internal Medicine, College of Medicine, Cheju National University, Jeju, Korea and ${ }^{4}$ Division of Allergy/Immunology, Department of Medicine, University of Tennessee, Memphis, TN, USA

Email: Nacksung Kim - nacksungkim@chonnam.ac.kr; Soon Seog Kwon - sskwon@cathoric.edu; Jaechun Lee - doc4u@hanmail.net; Sohyung Kim - doctor4u@empal.com; Tai June Yoo* - tyoo@utmem.edu

* Corresponding author

Published: 20 February 2006

Clinical and Molecular Allergy 2006, 4:4 doi:10.1 I86/I476-796I-4-4
Received: II October 2005

Accepted: 20 February 2006

This article is available from: http://www.clinicalmolecularallergy.com/content/4/1/4

(c) 2006 Kim et al; licensee BioMed Central Ltd.

This is an Open Access article distributed under the terms of the Creative Commons Attribution License (http://creativecommons.org/licenses/by/2.0), which permits unrestricted use, distribution, and reproduction in any medium, provided the original work is properly cited.

\begin{abstract}
Background: Vaccination with naked DNA encoding antigen induces cellular and humoral immunity characterized by the activation of specific ThI cells.

Objective: To evaluate the effects of vaccination with mixed naked DNA plasmids encoding Der $p$ I, $\operatorname{Der} p 2, \operatorname{Der} p$ 3, $\operatorname{Der} f$ I, $\operatorname{Der} f 2$, and $\operatorname{Der} f$ 3, the major house dust mite allergens on the allergic inflammation to the whole house dust mites (HDM) crude extract.

Methods: Three hundred micrograms of these gene mixtures were injected into muscle of BALB/ c mice. Control mice were injected with the pcDNA 3.I blank vector. After 3 weeks, the mice were actively sensitized and inhaled with the whole house dust mite extract intranasally.

Results: The vaccinated mice showed a significantly decreased synthesis of total and HDM-specific IgE compared with controls. Analysis of the cytokine profile of lymphocytes after challenge with HDM crude extract revealed that mRNA expression of interferon- $\gamma$ was higher in the vaccinated mice than in the controls. Reduced infiltration of inflammatory cells and the prominent infiltration of CD8+ T cells were observed in histology of lung tissue from the vaccinated mice.
\end{abstract}

Conclusion: Vaccination with DNA encoding the major house dust mite allergens provides a promising approach for treating allergic responses to whole house dust mite allergens.

\section{Background}

It has been reported that IgE-mediated inflammation to mites is associated with diseases such as asthma, allergic rhinitis, and atopic dermatitis and that the relatively minor determinants of house dust mite (HDM) allergens show IgE binding with $40 \%$ or more of allergic sera [1-4].
The most frequently implicated allergens are derived from Dermatophagoides pteronyssinus (Der p) and Dermatophagoides farinae (Der f) [5]. Targeting specific T lymphocytes that induce or regulate the allergic inflammation is one of the therapeutic goals in allergic disorders. Specific immunotherapy with crude extracts has been used mainly in 
treating HDM-induced allergy. However, it has limited efficacy. Recently, vaccinations with naked DNA encoding antigen were reported to induce long-lasting cellular and humoral immune tolerance $[6,7]$. Injection of plasmid DNA encoding T cell epitopes could suppress allergic reaction $[8,9]$. However, the potential barrier to T cell receptor-based immunotherapy for allergy is the apparent complexity of the allergen-specific $\mathrm{T}$ cell response in terms of epitope usage in individuals [10]. A recent literature search showed that injection of plasmid DNA encoding $\operatorname{Der} p 5$ in rat not only inhibits $\operatorname{Der} p$ 5-specific IgE antibody production but also an allergic response such as histamine release and airway hyperresponsiveness to $\operatorname{Der} p 5$ [11]. However, Der $p 5$ is not one of the major HDM allergens; thus, it has limited clinical application [3]. In this study, we investigated immune responses by gene vaccination with plasmid DNA encoding major HDM allergens (Derp 1,2, and 3, and $\operatorname{Der} f 1,2$, and 3) to challenges with whole HDM crude extract in sensitized mice.

\section{Methods \\ Animals}

Twenty female BALB/c mice 6-8 weeks old were purchased from Jackson Laboratory (Bar Harbor, ME) and bred in the animal facility of the University of Tennessee Health Science Center. This study was performed in accordance with the PHS Policy on Humane Care and Use of Laboratory Animals and the NIH Guide for the Care and Use of Laboratory Animal Welfare Act (7 U.S.C. et seq.). The animal use protocol was approved by the Institutional Animal Care and Use Committee (IACUC) of the University of Tennessee.

\section{Plasmid construction}

Total mRNA was isolated from Der $p$ and $\operatorname{Der} f$ HDM, respectively. By using murine leukemia virus reverse transcriptase and random hexanucleotide primer following the instructions of the Perkin Elmer Gene Amp RNA PCR kit (Perkin Elmer, Branchberg, NJ), first-strand cDNA was generated from $1 \mu \mathrm{g}$ of total RNA and subjected to reverse transcriptase polymerase chain reaction (RT-PCR). The cDNA was used in PCR with Taq polymerase with primers specific for $\operatorname{Der} p 1$ (5'- CCGGAATTCGCCGCCACCATGGAAACTAACGCCTGCAGTATCAATGGA -3' and 5'TGCTCTAGATTAGAGAATGACAACATATGGATATTC -3'), Der p 2 (5'- CCGGAATTCGCCGCCACCATGGATCAAGTCGATGTCAAAGATTGTGCC $-3^{\prime}$ and 5'TGCTCTAGATTAATCGCGGATTTTAGCATGAGTAGCAAT -3'), Der p 3 (5'- CCGGAATTCGCCGCCACCATGATTGTTGGTGGTGAAAAAGCATTAGCTG $-3^{\prime}$ and 5'TGCTCTAGATTACTGTGAACGTTTTGATTCAATCCAATCGATA -3'), Der $f 1$ (5'- CCGGAATTCGCCGCCACCATGGAAACAAGCGCTTGCCGTATCAATTCG $-3^{\prime}$ and 5'TGCTCTAGATTAGAGGTTGTTTCCGGCTT-

GGAAATATCCG -3'), Der $f \quad 2 \quad$ (5'-

CCGGAATTCGCCGCCACCATGGATCAAAGTCGATGTTAAAGATTGTGCC -3' and 5'- TGCTCTAGATTAATCACGGATTTTACCATGGGTAGCAAT -3'), and Der $f 3$ (5'CCGGAATTCGCCGCCACCATGATTGTTGGTGGTGTGAAAGCACAAGCC -3' and 5'- TGCTCTAGATTACTGTGAACGTTTTGATTCAATCCAATCGAC -3'). These primers cover the mature excreted region of each gene and include EcoR1 and Xb1 sites for cloning. The amplified PCR products were subcloned into pcDNA3.1 eukaryotic expression vector (Invitrogen, San Diego, CA) and then sequenced to verify the insertion of the correct gene with the appropriate open reading frame.

\section{DNA preparation and vaccination}

Each plasmid construct was prepared using Maxi prep (Quiagen, Chatsworth, CA). Mice were vaccinated by injection with $300 \mu \mathrm{g}$ of pcDNA3.1 blank vector in $100 \mu \mathrm{l}$ of phospate-buffered saline (PBS) (the control group) or the same amount of the mixed naked DNA encoding the major HDM allergens (the vaccination group) three times at weekly intervals into muscle (week 0, 1, and 2).

\section{Immunization and inhalation of allergen}

Mice were sensitized with HDM crude extract previously described [12]. HDM crude extract was emulsified with an equal volume of complete Freund adjuvant (CFA) for immunization. Three weeks after the last vaccination, mice were sensitized subcutaneously at the base of the tail with $100 \mu \mathrm{g}$ of HDM extract in CFA. The mice were also given an intraperitoneal dose of $300 \mathrm{ng}$ of purified pertussis toxin at 24 and $72 \mathrm{~h}$ after first immunization. Seven days later, the mice were boosted again with the same amount of antigen in incomplete Freund adjuvant. Under inhaled anesthesia with methoxyflurane, mice were challenged with $10 \mu \mathrm{g}$ of HDM crude extract through one nostril six times at weekly intervals after immunization.

\section{Determining total IgE, HDM-specific IgE, and HDM- specific IgG}

The blood from the six mice in two groups was collected six times at week 0 (first vaccination), 3, 5 (first immunization), 7, 9, and 11. The HDM-specific IgG was determined by ELISA. One hundred microliter of HDM ( $5 \mu \mathrm{g} /$ $\mathrm{ml}$ in $0.1 \mathrm{M}$ carbonate buffer, $\mathrm{pH}$ 9.6) were dispensed in each well of a polystyrene microtiter plate (Cost, Cambridge, MA) and incubated overnight at $4{ }^{\circ} \mathrm{C}$. The concentration of HDM was determined by the preliminary experiments. The antigen-coated plates were washed three times in $0.05 \%$ PBS-Tween 20 buffer (washing buffer) and incubated with mice sera overnight at $4^{\circ} \mathrm{C}$. The plates were washed five times with washing buffer and incubated with peroxidase-conjugated anti-mouse IgG antibody (Sigma, St. Louis, MO) overnight at $4^{\circ} \mathrm{C}$. The plates were washed five times before adding citric acid-phosphate buffer ( $\mathrm{pH} 5.0$ ) containing $0.15 \mathrm{mg} / \mathrm{ml}$ of $\mathrm{O}$-phe- 
nylenediamine (Sigma, St. Louis, MO). The color was developed at room temperature, and the reaction was stopped by $2.5 \mathrm{M}$ sulfuric acid. The color was measured at 492 nm (Bio-Rad, Richmond, CA).

The total IgE level was determined by ELISA. One hundred microliter of anti-mouse IgE capture monoclonal antibody (mAb) (clone R35-72; Pharmingen, San Diego, CA) were added in each well to plates and incubated overnight at $4{ }^{\circ} \mathrm{C}$. After washing, $200 \mu \mathrm{L}$ of $10 \%$ fetal calf serum were incubated at room temperature for $30 \mathrm{~min}$. The plates were washed five times with washing buffer and incubated with the diluted mouse serum overnight at $4{ }^{\circ} \mathrm{C}$, followed by adding $100 \mu \mathrm{L}$ of HRP-conjugated anti-mouse IgE detection mAb (clone R35-118; Pharmingen, San Diego, CA) overnight at $4{ }^{\circ} \mathrm{C}$. After washing, color was developed following the procedure for IgG. The purified mouse serum IgE (BD Biosciences, Palo Alto, CA) was used for total IgE standard. To measure HDM-specific IgE, the plate was coated with $25 \mu \mathrm{g} / \mathrm{ml}$ HDM in $0.1 \mathrm{M}$ carbonate buffer ( $\mathrm{pH}$ 9.6), and serum samples were diluted fivefold in $10 \%$ FCS. The concentration of HDM was determined by the preliminary experiments. The procedure after this point was the same as that for measuring HDM-specific IgG. The level of HDM-specific IgE was referenced to the standard serum pooled from six mice that were immunized with $100 \mu \mathrm{g}$ of HDM twice and inhaled with $10 \mu \mathrm{g}$ of antigen six times. The standard serum was calculated as 100 ELISA units/ml.

\section{Immunohistochemical staining for CD4+ and CD8+ T cells in lung tissue}

The lung tissues from the vaccination and control groups were removed immediately after the final intranasal inhalation. Tissues were fixed with periodate-lysine-paraformaldehyde solution for $24 \mathrm{~h}$ at $4{ }^{\circ} \mathrm{C}$. The specimens were rinsed with $0.01 \mathrm{M}$ of $\mathrm{PBS}(\mathrm{pH} 7.4$ ) containing $10 \%$ to $20 \%$ sucrose for $36 \mathrm{~h}$ at $4{ }^{\circ} \mathrm{C}$, embedded in OCT compound (Miles Laboratories Inc., Elkhart, IN), and immediately frozen. The lung specimens were immersed in $10 \%$ EDTA and decalcified for 10 days at $4{ }^{\circ} \mathrm{C}$. Frozen sections cut at 4 to $6 \mu \mathrm{m}$ in thickness were dehydrated and rinsed in cold PBS. The endogenous pseudoperoxidase was blocked with absolute methanol containing $0.5 \%$ hydrogen peroxide for $20 \mathrm{~min}$ at room temperature. The sections were treated with $10 \%$ normal goat serum in PBS to reduce nonspecific binding. Biotin conjugated rat antimouse CD8 or CD4 mAb (Pharmingen, San Diego, CA) diluted to 1:200 in PBS containing $0.5 \%$ bovine serum albumin was applied to the sections and incubated overnight at $4{ }^{\circ} \mathrm{C}$. After rinsing, the sections were incubated with avidin-biotin peroxidase complexes (Vectastain Elite ABC Kit, Vector Laboratories Inc., Burlingame, CA) for 30 min at room temperature and rinsed sufficiently with PBS. The reaction was developed with $0.02 \% 3,3$ '-diaminoben- zidine in $0.05 \mathrm{M}$ of Tris buffer (pH 7.6) with $0.005 \%$ hydrogen peroxidase for $7 \mathrm{~min}$. The sections were dehydrated, cleared in xylene, and mounted.

\section{Histological examination of lung tissue}

Mice were anesthetized with a mixture of ketalar $(35 \mathrm{mg} /$ $\mathrm{ml})$, rompun $(0.6 \% / \mathrm{ml})$ and atropine $(0.1 \mathrm{mg} / \mathrm{ml})$, of which $0.2 \mathrm{ml}$ was injected intramuscularly. The vascular bed of the lungs was perfused with $0.01 \mathrm{M}$ PBS and then with $4 \%$ paraformaldehyde $0.1 \mathrm{M}$ PBS buffers. Whole lungs were taken out and stored in $4 \%$ paraformaldehyde for $24 \mathrm{~h}$ at $4{ }^{\circ} \mathrm{C}$. After fixation, these tissues were dehydrated and embedded in paraffin. Frozen sections cut at 3 $\mu \mathrm{m}$ in thickness were stained by hematoxylin and eosin. After coding, the sections were evaluated by two observers using light microscopy. The amount of inflammation per section was scored using the method described by Hessel et al. [13]. Lungs that showed no focal inflammation were scored as grade 0 . Those that showed one or two centrally located microscopic foci of inflammatory infiltrate were graded as 1 . In grade 2 , a dense inflammatory infiltrate was seen in a perivascular and peribronchial distribution originating in the center of the lung. In grade 3, the perivascular and peribronchial infiltrates extended to the periphery of the lung.

\section{Measuring cytokine mRNA expression}

Measuring the expression level was done as previousy described [9]. Briefly, four mice from each group were sacrificed 10 days postboost. The lymph nodes were removed from the mice and minced to create single cell suspensions. Cells were cultured in RPMI for $18 \mathrm{~h}$ with no antigen as a negative control, recombinant $\operatorname{Der} p 1(100 \mu \mathrm{g} /$ $\mathrm{ml})$, or HDM crude extract $(100 \mu \mathrm{g} / \mathrm{ml})$. Cells were washed with PBS buffer and mRNAs prepared (Biotech, Houston, TX). By using murine leukemia virus reverse transcriptase and random hexanucleotide primer following the instructions of the Perkin Elmer Gene Amp RNA PCR kit (Perkin Elmer, Branchber, NJ), first-strand cDNA was generated from $1 \mu \mathrm{g}$ of total RNA and subjected to RTPCR analysis. We used the primers specific for $\beta$-actin (5'GTGGGCCGCTCTAGGCACCAA - 3 ' and 5'- CTCTTTGATGTCACGCACGATTTC -3') as control primer, IL-2 (5'TTCAAGCTCCACTTCAAGCTCTACAGCGGAAG - $3^{\prime}$ and 5'- GACAGAAGGCTATCCATCTCCTCAGAAAGTCC -3'), IFN- $\gamma$ (5' - TGCATCTTGGCTTTGCAGCTCTTCCTCATGGC $-3^{\prime}$ and 5'- TGGACCTGTGGGTTGTTGACCTCAAACT TGGC -3') (Clonetech, Palo Alto, CA), IL-4 (5'CAGCTAGTTGTCATCCTGCTCTTC - 3 ' and 5'- GTGATGTGGACTTGGACTCATTCATGG -3'), or IL-5 (5'- TGTCTGGGCCACTGCCATGGAGATTC $-3^{\prime}$ and 5'CCATTGCCCACTCTGTACTCATCACAC - $3^{\prime}$ ) in the RTPCR analysis. The amplified DNAs of $\beta$-actin, IFN- $\gamma$, IL-2, IL-4, and IL-5 were 540, 365, 413, 354, and 349 base pairs, respectively. 

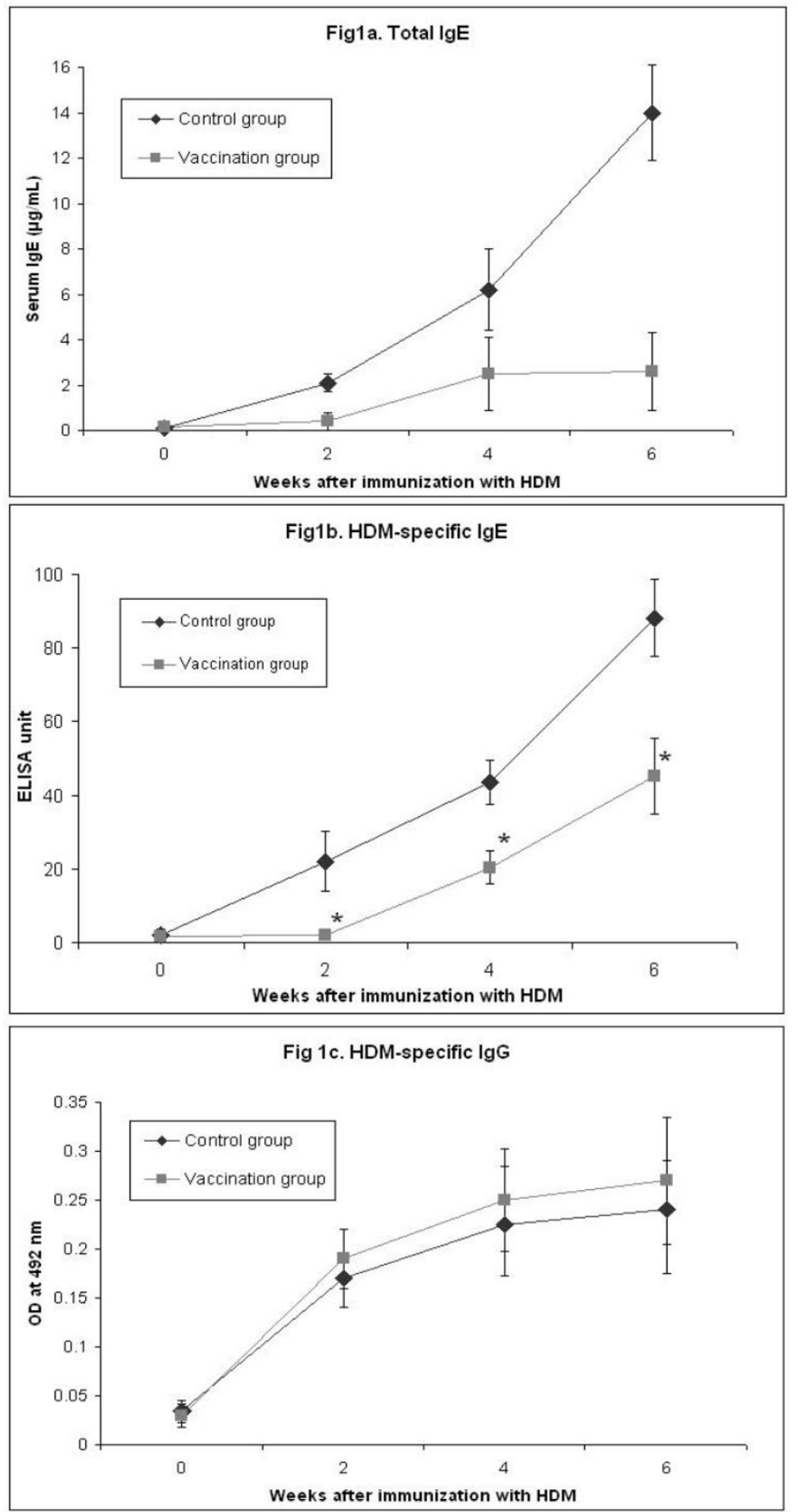

\section{Figure I}

Effect of vaccination on immunoglobulin production. The total IgE antibody levels (Ia), HDM-specific lgE antibody levels (Ib), and HDM-specific IgG antibody levels (Ic) in sera of each mouse were detected by ELISA every 2 weeks after immunization with HDM. The data are expressed as means \pm SD $(n=6$ per group). $* P<.05$ compared with the control group. 


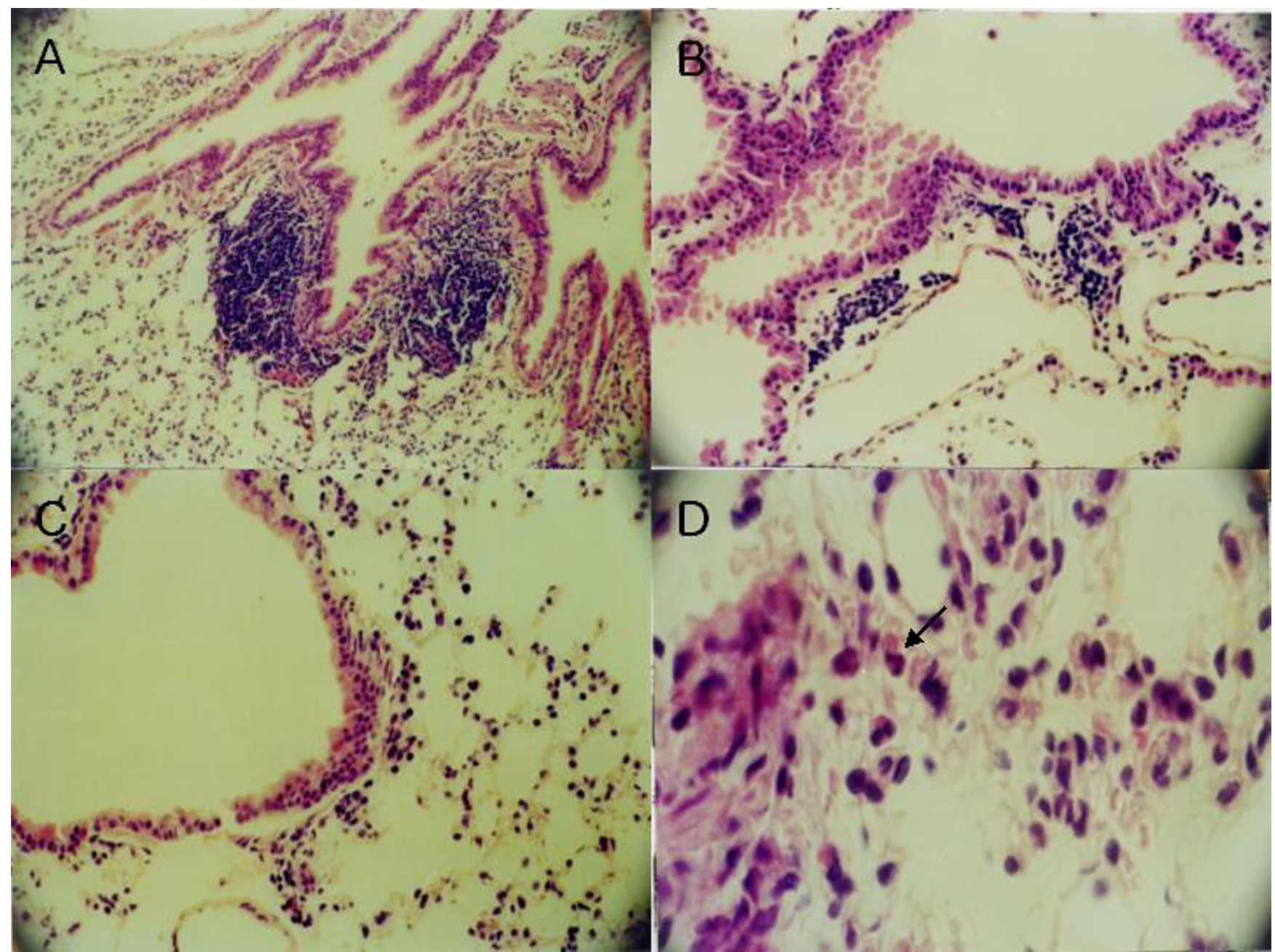

\section{Figure 2}

Effect of genetic vaccination on lung histopathology in an animal model of allergy. A and B, Light microscopic examinations of lung tissue from control group mouse $(\times 100$ and $\times 200)$. C, From vaccination group mouse $(\times 200)$. D, Inflammatory cells including eosinophils (indicated with arrow) were observed in the peribronchial area in lung tissue from control group $(\times 600)$. All tissue samples were stained with hematoxylin and eosin.

\section{Statistical analysis}

Data in immunoglobulin response were analyzed by Student's paired $t$ test for comparisons between control and vaccination groups. Histological grades were analyzed by a nonparametric Mann-Whitney U test. Data were expressed as mean \pm SD. A $p$-value of $<0.05$ was considered significant.

\section{Results}

\section{Downregulation of allergen specific IgE production by DNA vaccination}

DNA vaccination with the major HDM allergen gene, Der $p$ 1, 2, and 3, and $\operatorname{Der} f 1,2$, and 3 showed about 50\% reduction of HDM-specific IgE and more than $70 \%$ reduction of total IgE compared with the control group at 6 weeks after immunization (Fig. 1a and 1b). However, pro- duction of HDM-specific IgG antibody showed no difference (Fig. 1c). Thus, in vivo total and allergen-specific IgE synthesis might be efficiently inhibited by DNA vaccination.

\section{Histological and immunohistochemical study}

To investigate whether the DNA vaccination affects inflammation of lung, we stained lung tissue by histological and immunohistochemical methods. The lungs from the control group showed much more infiltration of inflammatory cells in the submucosa of airways than did those lungs from the vaccination group. The inflammation grades were scored as $1.64 \pm 0.52$ (mean \pm SD) in the control group and $0.68 \pm 0.48$ in the vaccination group (Fig. 2a, 2b, and 2c). Also, eosinophils were detected in the lungs of the control mice (Fig. 2d). In the immunohis- 


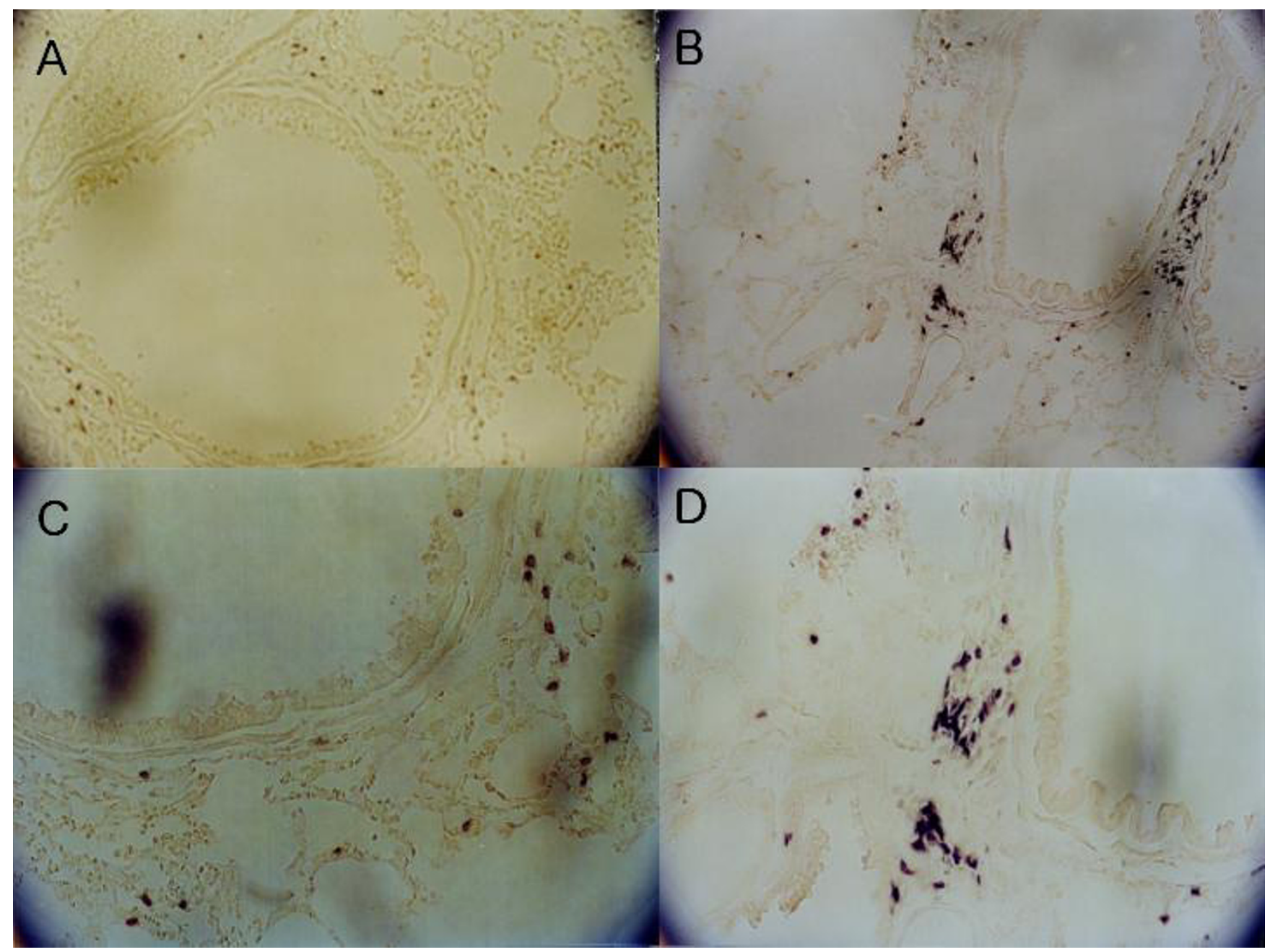

\section{Figure 3}

Immunohistochemical examination for CD8+ T cells in lung tissue. In the lung tissue from the vaccination group, more CD8+ T cells were infiltrated along the airway than in control group. $A$ and $B$, Lung tissue from control group mouse $(\times 100$ and $\times 200)$. C and D, Vaccination group $(\times 100$ and $\times 200)$. Immunohistochemical staining with rat anti-mouse CD8 monoclonal antibody.

tochemical stain for CD4 and CD8 molecules, the more CD8+ cells were infiltrated in the submucosa and mucosa of airway from the vaccination group compared with the control group (Fig. 3). But no difference in CD4+ cells was shown between the two groups. We considered whether the DNA vaccination might have an effect on the cellular response and the $\mathrm{CD} 8+\mathrm{T}$ cells, which might protect against subsequent allergen challenges.

\section{Cytokines expressed by antigen stimulation}

Lymphocytes were harvested from lymph nodes of the two groups of mice and stimulated with recombinant Der $p 1$ or HDM crude extract to determine the Th1 or Th2 cytokines involved in the DNA vaccination. Significantly elevated expression of IFN- $\gamma$ mRNA was detected in the vaccination group compared with that in the control group. However, mRNA expression of IL-2, 4, 5, and 10 showed no difference from the control group (Fig. 4).

\section{Discussion}

Diseases such as allergic asthma, rhinitis, and atopic dermatitis are all characterized by elevated levels of serum IgE. Total and specific IgE levels also show a close relationship with clinical symptoms in atopic allergy [14]. A variety of approaches targeting the suppression of IgE have been proposed such as synthetic peptides and $\mathrm{T}$ cell vaccine. However, synthetic peptides have substantial limitations because of poor immunogenecity $[15,16]$. Recently, in an animal model of allergic disorders, DNA vaccine encoding one of the major birch pollen allergens has been shown to be allergen-specifically protective and therapeutic [17]. DNA vaccination with plasmid encoding Der $p$ 5, 


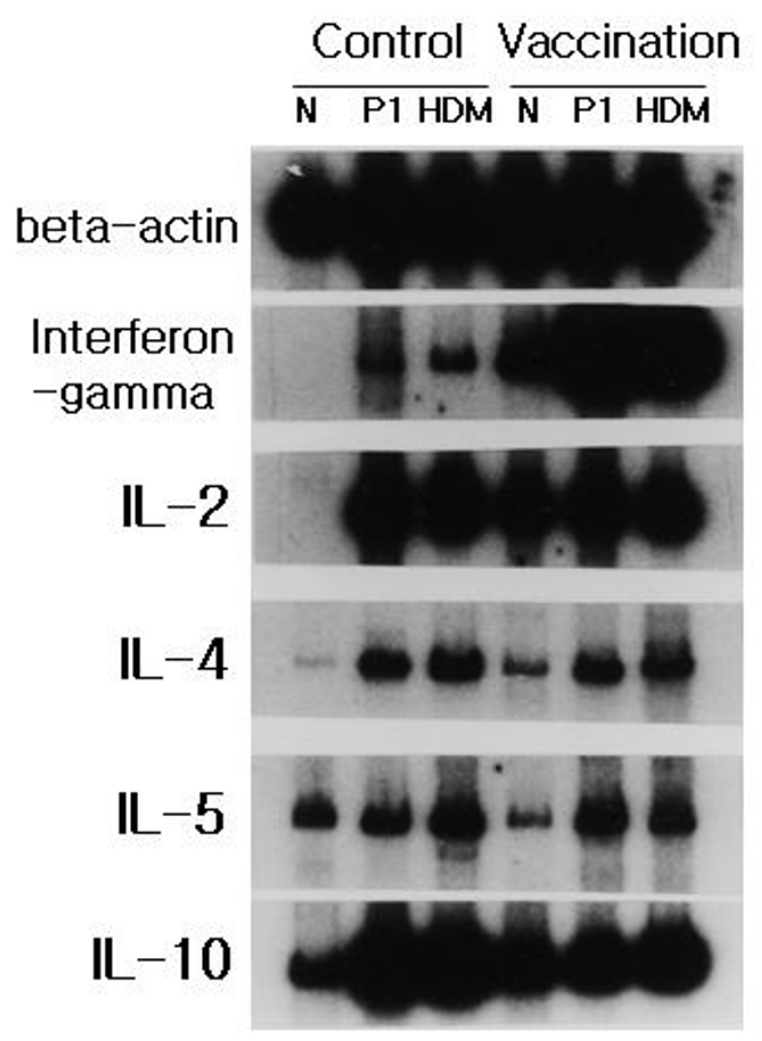

\section{Figure 4}

Cytokine expression in lymphocytes. Lymphocytes from the control group and vaccination group were cultured in the presence of no antigen $(\mathrm{N})$, recombinant Der $p \mathrm{I}(\mathrm{PI})$, and HDM crude extract (HDM) for $18 \mathrm{~h}$. mRNAs of each indicated cytokine (interferon-gamma, IL-2, IL-4, IL5, IL- I0) were measured by RT-PCR and that of beta-actin was measured for control.

one of the minor HDM allergens, was reported to prevent induction of specific IgE synthesis [11]. Vaccination with pDNA encoding Der $p 5$ was shown to induce Th1 immune response to the encoded antigens. However, these results have some limitations on the clinical application for treating allergic disorders. Each allergen that causes allergic disorders in humans contains various kinds of protein that have their own epitopes and are complex. The Der $p 5$ allergen reacts with about only $40 \%$ of allergic sera to HDM, and the Der $p 1$ and 2 allergens react with about $80 \%$ of allergic sera $[3,5]$. To evaluate the effect of the gene vaccination with DNA fragments encoding major allergen on the allergic response to whole HDM extract, we used plasmid with cDNAs encoding the major six HDM allergens $(\operatorname{Der} p 1,2$, and 3, and $\operatorname{Der} f 1,2$, and 3) for vaccination. We showed about $50 \%$ reduction of HDM-specific IgE and more than $70 \%$ inhibition of total
IgE at 6 weeks after immunization compared with control group. DNA vaccine with plasmid encoding the major HDM allergens might inhibit IgE synthesis more efficiently than encoding one of the HDM allergens.

In animal models of allergic disease, it has been established that Th2 responses are mediated by $\mathrm{T}$ helper cells that secret cytokines such as IL-4 and IL-5, which induce antibody production in B cells, and IgE plays a central role in allergic responses [18]. IFN- $\gamma$ is the Th1 cytokine responsible for inhibiting IL-4-mediated IgE responses and promoting the formation of IgG2a [19]. Plasmid vector containing DNA that encodes allergens has been reported to decrease Th2-mediated responses, enhance Th1 responses, and suppress the allergic response $[11,20,21]$. In this investigation, mRNA expression of IFN- $\gamma$ in lymphocytes from the vaccination group increased significantly relative to that from the control group, and less production of total and specific IgE in the vaccinated group was detected than in the control group, suggesting that the gene vaccination might successfully redirect the immune response from Th2 into Th1 to the encoded antigen or allergen.

Allergic asthma is characterized as a chronic inflammatory disease of the bronchi. It is well established that a variety of cells including mast cells, eosinophils, and lymphocytes play a role in this process $[22,23]$. After inhalation challenges, the inflammatory cells migrate from the peripheral blood to the site of inflammation in the bronchial mucosa, and Th2 type cytokines are dominantly detected in bronchoalveolar lavage fluid [24,25]. However, our investigation showed that DNA vaccination successfully reduced the recruitment of inflammatory cells in lung tissues. The effect of DNA vaccination in allergic inflammation might be elicited through not only humoral immune responses but also cellular responses.

$\mathrm{T}$ lymphocytes have been suggested to play a key role in orchestrating the interaction of the participating cells since they are able to release an array of cytokines that can attract, prime, and activate other cell types [25]. A successful outcome of immunotherapy is known to be associated with the development of regulatory $\mathrm{T}$ cells, which can downregulate the allergic response [26-30]. It is also known that functionally distinct subsets of CD8+ T cells may play an important regulatory role in IgE production [30-32]. However, there are some different explanations regarding the mechanisms of DNA vaccine. Manickan et al. [33] demonstrated the mechanism of genetic immunization against herpes simplex virus principally by CD $4+\mathrm{T}$ cells, not by CD8+ T cells. Lee et al. [22] reported that both CD4+ and CD8+ subsets of T cells from pDNA vaccinated mice can suppress IgE antibody production by affecting the primary response or by propagating the Th 1 memory 
response in a passive cell transfer system. Draghi et al. [34] investigated whether DNA vaccination leads to the generation of a distinct population of noncytotoxic/regulatory CD8+ T cells. In the authors' immunohistochemical investigation, more CD8+ T cells were more infiltrated in the lung tissue of the vaccination group than that of the control group.

Peptides derived from extracellular molecules are presented to CD4+ T cells by MHC (histocompatibility complex) class II molecules normally generated by antigenpresenting cells, whereas peptides derived from intracellular proteins are generally presented to CD8+ T cells by MHC class I molecules, which are expressed on virtually all somatic cells [35]. We injected mixed naked DNA into the muscle of the murine model of allergic disorder. Some of the injected DNA might be postulated to stay in the nuclei of cells or be integrated in the host DNA and elicit the endogenous production of an allergenic protein. MHC class I molecule, might induce CD8+ T cells that protectively function in immune response against a subsequent allergic challenge in sensitized host cells. The CD8+ $\mathrm{T}$ cells might be capable of conferring protection from allergic inflammation. DNA vaccination, which contains plasmid and DNA encoding specific allergen, might provide a more efficient therapeutic method for intervening allergic responses than conventional specific immunotherapy with allergen extracts.

\section{Abbreviations}

HDM : house dust mite

pDNA : plasmid DNA

\section{Authors' contributions}

$\mathrm{N}$ Kim and SS Kwon carried out animal and molecular experiments and initial draft. J Lee and S Kim handled images of the draft and final draft. TJ Yoo supported the whole step of experiment and submission.

\section{References}

I. Platts-Mills TAE, Chapman MD: Dust mites, immunology, allergic disease, and environmental control. J Allergy Clin Immunol 1987, 80:755-775

2. Lin KL, Hsieh KH, Thomas WR, Chiang BL, Chua KY: Allergens, IgE, mediators, inflammatory mechanisms. Characterization of Der $p 5$ allergen, cDNA analysis, and IgE-mediated reactivity to the recombinant protein. I Allergy Clin Immunol 1994, 94:989-996.

3. International workshop report: Dust mite allergens and asthma: a world wide problem. WHO Bulletin 1988, 66:769-780

4. Van der, Zee JS, Van Swieten P, Janse HM, Aalberse RC: Skin tests andhistamine release with PI-depleted Dermatophagoides pteronyssinus body extracts and purified P I. J Allergy Clin Immunol 1988, 81:884-895.

5. Thomas WR: Mite allergens groups I-VII. A catalogue of enzymes. Clin Exp Allergy 1993, 23:350-353.

6. Raz E, Carson DA, Parker SE, Par TB, Abai AM, Aichinger G: Intradermalgene immunization: the possible role of DNA uptake in the induction of cellular immunity to viruses. Proc Natl Acad Sci U S A 1994, $91: 9519-9523$.
7. Reyes-Sandoval A, Ertl HC: DNA vaccines. Curr Mol Med 200I, I:217-243.

8. Ruiz PJ, Garren H, Ruiz IU, Hirschberg DL, Nguyen LV, Karpuj MV, et al: Suppressive immunization with DNA encoding a self-peptide prevents autoimmune disease: modulation of $\mathrm{T}$ cell costimulation. J Immunol 1999, 162:3336-334I.

9. Kwon SS, Kim N, Yoo T]: The effect of vaccination with DNA encoding murine T-cell epitopes on the Der $p \quad I$ and 2 induced immunoglobulin E synthesis. Allergy 200I, 56:74I-748.

10. Lewis DB: Allergy immunotherapy and inhibition of Th2 immune responses: a sufficient strategy? Curr Opin Immunol 2002, 14:644-65।

II. Hsu CH, Chua KY, Tao MH, Lai YL, Wu HD, Huang SK, et al:: Immunoprophylaxis of allergen-induced immunoglobulin $E$ synthesis and airway hyperresponsiveness in vitro by genetic immunization. Nature Med 1996, 2:540-544.

12. Cheng KC, Lee KM, Krug MS, Watanabe T, Suzuki M, Choe IS, et al: House dust mite-induced sensitivity in mice. J Allergy Clin Immunol 1998, 101:51-59.

13. Hessel EM, Van Oosterhout AJ, Hofstra CL, De Bie J], Garssen J, Van Loveren $\mathrm{H}$, et al:: Bronchoconstriction and airway hyperresponsiveness after ovalbumin inhalation in sensitized mice. Eur J Phamacol 1 995, 93:240 I-4I2.

14. Droste JH, Kerkhof M, de Monchy Jan GR, Schouten Jan P, Rijcken B, Dutch ECRHS group: Association of skin test reactiviy, specific IgE, total IgE, and eosinophils with nasal symptoms in a community-based population study. J Allergy Clin Immunol 1996, 97:922-932.

15. Bot A, Bot S, Karjalainen K, Bona C: Kinetics of generation and persistence on membrane class II molecules of a viral peptide expressed on foreign and self proteins. J Immunol 1996 , I 57:3436-3442.

16. Demotz S, Grey HM, Sette A: The minimal number of class II MHC-antigen complexes needed for $\mathrm{T}$ cell activation. Science 1990, 249: 1028-1030.

17. Hartl A, Hochreiter R, Stepanoska T, Ferreira F, Thalhamer J: Characterization of the protective and therapeutic efficiency of a DNA vaccine encoding the major birch pollen allergen Bet $v$ Ia. Allergy 2004, 59:65-73.

18. Maggi E: The THI/TH2 paradigm in allergy. Immunotechnology 1998, 3:233-244.

19. Snapper CM, Paul WE: Interferon- $\gamma$ and B cell stimulatory factor-I reciprocally regulate Ig isotype production. Science 1987, 236:944-947.

20. Lai WC, Bennett M, Johnston SA, Barry MA, Pakes SP: Protection against Mycoplasma pulmois infection by genetic vaccination. DNA Cell Biol 1995, 14:643-65I.

2I. Huygen K, Content J, Denis O, Montgomery DL, Yawman AM, Deck $R R$, et al.: Immunogenicity and protective efficacy of a tuberculosis DNA vaccine. Nature Medicine 1996, 2:893-898.

22. Lee DJ, Tighe H, Corr M, Carson DA, Spiegelberg HL, Raz E: Inhibition of IgE antibody formation by plasmid DNA immunization is mediated by both CD4+ and CD8+ T cells. Int Arch Allergy Immunol 1997, I I 3:227-230.

23. Krug N, Tshernig T, Holgate S, Pabst R: How do lymphocytes get intothe asthmatic airways? Lymphocyte traffic into and within the lung in asthma. Clin Exp Allergy 1998, 28:10-18.

24. Ying S, Durham SR, Cirrogan CJ, Hamid Q, Kay AB: Phenotype of cellsexpressing mRNA for Th2-type (interleukin 4 and interleukin 5) and Thl-type (interleukin 2 and interferon $\gamma$ ) cytokines in bronchoalveolar lavage and bronchial biopsies from atopic asthmatic and normal control subjects. Am J Respir Cell Mol Biol 1995, I 2:477-487.

25. Humbert M, Durham SR, Ying S: IL-4 and IL-5 mRNA and protein in bronchial biopsies from patients with atopic and nonatopic astham: evidence against 'intrinsic' asthma being a distinct immunopathologic entity. Am J Respir Crit Care Med 1996, I54:|497-I504.

26. Hsieh $\mathrm{KH}$ : Changes of lymphoproliferative responses of $\mathbf{T}$ cell subsets to allergen and mitogen after hyposensitization in asthmatic children. J Allergy Clin Immunol 1984, 74:34-40.

27. Hsieh $\mathrm{KH}$, Lue $\mathrm{KH}$, Chiang CF: Immunological changes after hyposensitization in house-dust-sensitive asthmatic children. J Asthma 1987, 24:19-27. 
28. Akbari O, Stock P, DeKruyff RH, Umetsu DT: Role of regulatory T cells in allergy and asthma. Curr Opin Immunol 2003, 1 5:627-633.

29. Akbari O, Freeman GJ, Meyer EH, Greenfield EA, Chang TT, Sharpe $\mathrm{AH}$, et al.: Antigen-specific regulatory $\mathbf{T}$ cells develop via the ICOS-ICOS-ligand pathway and inhibit allergen-induced airway hypersensitivity. Nat Med 2002, 8: I024-1032.

30. Kemeny DM, Diaz-Sanchez S: Role of CD8+T cells in rat IgE responses. Int Arch Allergy Appl Immunol I99I, 94:99-I0I.

31. McMenamin C, Holt PG: The natural immune response to inhaled soluble protein antigens involves major histocompatibility complex (MHC) class I restricted CD8+ T cellmediated but MHC class II-restricted CD4+T cell-dependent immune deviation resulting in selective suppression of immunoglobulin production. J Exp Med 1993, 178:889-899.

32. Renz H, Lack G, Salog J, Schwinzer R, Bradley K, Loader J, et al.: Inhibition of IgE production and normalization of airways responsiveness by sensitized CD8+ $T$ cells in a mouse model of allergen-induced sensitization. J Immunol 1994, I 52:35I-360.

33. Manickan E, Rouse RJD, Yu Z, Wire WS, Rouse BT: Genetic immunization against herpes simplex virus: protection is mediated by CD4+ T lymphocytes. J Immunol 1995, 1 55:259-265.

34. Draghi M, Jarman ER, Grifantini R, Galli-Stampino L, Lamb JR, Valiante NM, et al.: Different profile of CD8+ effector $\mathbf{T}$ cells induced in Der pl-allergic and naïve mice by DNA vaccination. Eur J Immunol 2002, 32:3720-3728.

35. Germain RN, Margulies DH: The biochemistry and cell biology of antigen processing and presentation. Annu Rev Immumol I993, I I:403-450.

Publish with Bio Med Central and every scientist can read your work free of charge

"BioMed Central will be the most significant development for disseminating the results of biomedical research in our lifetime. "

Sir Paul Nurse, Cancer Research UK

Your research papers will be:

- available free of charge to the entire biomedical community

- peer reviewed and published immediately upon acceptance

- cited in PubMed and archived on PubMed Central

- yours - you keep the copyright

Submit your manuscript here:

http://www.biomedcentral.com/info/publishing_adv.asp
BiolMedcentral 